\title{
Blast Cells with Monoclonal Surface Immunoglobulin in Two Cases of Acute Blast Crisis Supervening on Chronic Lymphocytic Leukaemia
}

\begin{abstract}
Summary
Acute blast crisis occurred in two patients with previously well-confirmed chronic lymphocytic leukaemia. The finding by direct immunofluorescence of membranebound monoclonal immunoglobulins on the surface of the blast cells showed that they were related to $B$ cells in the same way as the proliferating lymphocytes in most patients with chronic lymphocytic leukaemia. In one patient the surface monoclonal IgM detected on both the lymphocytes and the blast cells had the same rheumatoid antibody activity, supporting the concept that the leukaemic cells found during the acute and chronic phases of the disease originated from the same clone.
\end{abstract}

\section{Introduction}

The occurrence of an acute blast crisis supervening on chronic lymphocytic leukaemia has rarely been reported, and it has been suggested that in such cases there are two distinct and unrelated malignancies. Since membrane-bound immunoglobulins represent a useful marker of the monoclonal proliferation of B lymphocytes found in most cases of the disease (Preud'Homme and Seligmann, 1972 a), the finding of monoclonal immunoglobulins on the surface of the blast cells in two patients who developed a blast crisis after one and 20 years of well-documented chronic lymphocytic leukaemia is noteworthy. Moreover, in one of these patients the monoclonal IgM found on the small lymphocytes and on the blast cells was shown to have the same antibody activity, establishing that both types of proliferating cells originated from the same clone.

\section{Patients and Methods}

\section{CASE 1}

A 60-year-old Egyptian was first seen in Paris in 1972 with the clinical and haematological features of acute leukaemia. Twenty years before the diagnosis of chronic lymphocytic leukaemia had been established on the basis of a moderate splenomegaly with peripheral blood and bone marrow lymphocytosis. At that time the W.B.C. was $29,000 / \mathrm{mm}^{3}$ (polymorphonuclear neutrophils $26 \%$, small mature lymphoctyes $76 \%$, atypical large lymphocytes $4 \%$ ). Several marrow aspirates showed a pronounced lymphocytosis (40 to $60 \%$ ). Treatment was not prescribed until October 1971. During this period the splenomegaly remained unchanged and numerous haematological examinations showed persistent lymphocytosis (W.B.C. 15,000 to $30,000 / \mathrm{mm}^{3}$ (60 to $80 \%$ small lymphocytes). In November 1971 anaemia, splenic en-

\footnotetext{
Research Institute on Blood Diseases, Hôpital Saint-Louis, Paris 10, France

JEAN-CLAUDE BROUET, M.D., Chef de Clinique Assistant

JEAN-LOUIS PREUD'HOMME, M.D., Chargé de Recherches à l'I.N.S.E.R.M

MAXIME SELIGMANN, M.D., Professor

JEAN BERNARD, M.D., Professor of Haematology
}

largement, and rising W.B.C. were the first manifestations of the acute phase of the disease. A blood count showed W.B.C. $40,000 / \mathrm{mm}^{3}$ with $87 \%$ blast cells, and a sternal marrow aspirate was described in Egypt as "hypercellular with gross lymphocytic activity and $25 \%$ of lymphoblasts with fine nuclear chromatin and definite nucleoli." Treatment with prednisone, vincristine sulphate, and cyclophosphamide was followed by a remission in April 1972. A relapse occurred in October, and the patient was referred to one of us. Examination disclosed pallor, purpuric spots, and massive splenomegaly. The blood count showed W.B.C. $200,000 / \mathrm{mm}^{3}$ with $96 \%$ blast cells. The bone marrow was hypercellular with total replacement by undifferentiated blast cells with one or more prominent nucleoli and cytoplasmic granules. Previous chemotherapy precluded a more precise cytological diagnosis; peroxidase staining of the cells was negative. The patient died shortly afterwards from acute myocardial infarction.

CASE 2

A 50-year-old white man was first seen in April 1971 for mild weakness. Examination disclosed a moderate hepatosplenomegaly. A blood count showed W.B.C. $16,000 / \mathrm{mm}^{3}$ with $80 \%$ small mature lymphocytes. Marrow aspirate showed $80 \%$ mature lymphocytes. Lymphangiograms showed a moderate hyperplasia of the retroperitoneal lymph nodes. Chlorambucil $6 \mathrm{mg} /$ day was started in September 1971 and was followed by clinical and haematological improvement-W.B.C. $5,200 / \mathrm{mm}^{3}$ ( $40 \%$ small lymphocytes). In March 1972 , as left-sided flank pains appeared striking changes in the haematological findings were discovered: W.B.C. $30,000 / \mathrm{mm}^{3}(80 \%$ blast cells), severe anaemia, and thrombocytopenia. Bone marrow examination showed $25 \%$ small mature lymphocytes and $50 \%$ large and vacuolated lymphoblasts. A remission was not achieved and the patient died in May 1972.

The direct immunofluorescence method was used for the study of membrane-bound immunoglobulins. The procedures used for the separation of blood lymphocytes and marrow lymphoid cells, for the selection and preparation of suitable monospecific antisera to $\mu-, \gamma-, a-, \kappa^{-}$, and $\lambda$-chains, for the preparation of rhodamine and fluorescein conjugates, and for the detection of surface immunoglobulin by staining in the cold of living cells in suspension have been described in detail elsewhere (Preud'Homme et al., 1971). Identification of lymphocytes or blast cells in counting of positive cells required alternative examination of each field in phase contrast and in ultraviolet light.

To investigate if the surface immunoglobulins were or were not actually synthesized by the cells which carried them, the cells were treated with trypsin and incubated in a culture medium for six to seven hours before staining (Preud'Homme and Seligmann, 1972 b). In one patient various experiments, including antibody induced redistribution of surface immunoglobulins and the demonstration of the ability of membranebound IgM newly synthesized in vitro to bind unaggregated human IgG, were performed in order to establish an anti-IgG (rheumatoid) antibody activity of the surface monoclonal IgM (Preud'Homme and Seligmann, 1972 c).

\section{Results}

In both patients the acute leukaemia occurred suddenly during 
the course of confirmed chronic lymphocytic leukaemia without any peculiar clinical or haematological features at the onset of the disease. The blast crisis showed itself by striking clinical and haematological changes. Anaemia, thrombocytopenia, rising blood counts, and severe splenomegaly appeared in a short period of time. Blast cells were present both in the peripheral blood and in the bone marrow, together with persisting small mature lymphocytes at the onset of the acute phase. No more lymphocytes were seen during the relapse in case 1 . In case 2 the blast cells were large lymphoblasts with vacuolated cytoplasm. In the other patient the blast cells, perhaps altered by the previous chemotherapy, were undifferentiated.

In the first case immunofluorescence studies showed that the blast cells were all labelled by the antisera to $\mu$ - and $\lambda$-chains and were not stained by the three other antisera. This surface monoclonal $\operatorname{IgM} \lambda$ was synthesized in vitro during short-term culture after removal of the immunoglobulins attached to the cell membrane by the use of trypsin. In the second case the residual small lymphocytes as well as the lymphoblasts were simultaneously stained by the antisera to $\mu-, \gamma^{-}, \kappa^{-}$, and $\lambda$ - chains. However, after removal of these surface immunoglobulins by treatment with trypsin, only $\mu$ - and $\kappa$-chains were detected at the cell surface after six hours of in-vitro culture. This newly synthesized monoclonal $\operatorname{IgM}$ was able to bind normal unaggregated human IgG. This finding, as well as various other experiments described elsewhere (Preud'Homme and Seligmann, $1972 \mathrm{c}$ ), indicated that we were dealing with an anti-IgG antibody activity of the surface monoclonal $\operatorname{IgM}$, and that the IgG binding occurred in vivo leading to the mixed immunofluorescence staining of the freshly drawn circulating lymphocytes and blast cells.

\section{Discussion}

In contrast to the occurrence of a minor population of immature lymphocytes, which is not uncommon in chronic lymphocytic leukaemia, the incidence of true acute leukaemia is low, ranging from 1 to $4 \%$ in various large series of patients with the disease (Osgood, 1964; Diamond et al., 1950; MacPhedran and Heath, 1970). In some cases (Osgood, 1964; Diamond et al., 1950; MacPhedran and Heath, 1970; Pequignot et al., 1970) the blast cells have been undifferentiated or were not precisely identified. Monoblastic or myelomonocytic leukaemias were documented in eight of the reported cases (Osgood, 1964; Lortholary et al., 1966; Catovsky and Galton, 1971) and acute myeloblastic leukaemia in one (Lortholary et al., 1966). Acute lymphoblastic leukaemia has been reported during the course of chronic lymphocytic leukaemia in only three patients (Boggs et al., 1962; Catovsky and Galton, 1971; MacPhedran and Heath, 1970) and in one patient with welldifferentiated lymphosarcoma (Lortholary et al., 1966). As in our second patient, the morphological characteristics of the blast cells in these cases were not those usually found in childhood acute lymphocytic leukaemia: the blasts were large basophilic cells with vacuolated and scant cytoplasm and rare granules.

The low incidence of acute leukaemia superimposed on chronic lymphocytic leukaemia together with the great variety of its cytological features precludes firm conclusions about its significance. The coincidental finding of two distinct malignant processes in the same patient seems unlikely. The recent reports of acute leukaemia occurring in patients treated for multiple myeloma (Kyle et al., 1970; Andersen and Videbaeck, 1970) or other malignant diseases support the hypothesis that in some cases the acute phase may be elicited by long-term chemotherapy. In several such cases the acute leukaemia was of the myelomonocytic type. In fact all previously reported patients with acute leukaemia supervening on chronic lymphocytic leukaemia except one (Boggs et al., 1962) had been treated with ${ }^{32} \mathrm{P}, x$-rays, or alkylating agents for more than two years. In our first patient, however, the acute phase occurred without previous chemotherapy, and in the second one the role of a limited course of chlorambucil seems doubtful. On the other hand, the immunodeficiency usually seen in patients with the disease may precipitate the occurrence of haematological as well as epithelial malignancies.

Whether or not the occurrence of acute leukaemia, as well as that of reticulum cell sarcoma (Richter's syndrome) (Lortholary et al., 1964), represents the emergence of a second unrelated malignant clone is questionable. Our findings strongly argue against such a possibility in our two patients since in both of them the blast cells studied during the acute phase carried a monoclonal surface IgM which was proved to be synthesized in vitro. These blast cells are therefore related to the $B$ lymphocytes in the same way as to the leukaemic lymphocytes of most patients with chronic lymphocytic leukaemia. Moreover, in one of our patients the same monoclonal $\operatorname{IgM} \varkappa$ with a similar anti-IgG antibody activity reflecting identical variable regions was found on the surface of the remaining lymphocytes and of the blast cells, showing that the proliferating cells involved in the chronic and in the acute phase of the disease originated from the same clone. Whether the blast cells are immature neoplastic B cells or "activated" malignant lymphocytes remains a matter of speculation.

Though true acute blast crisis is by all evidence a rare event in chronic lymphocytic leukaemia, surface monoclonal immunoglobulins provide a marker as useful as the Philadelphia chromosome in chronic granulocytic leukaemia in order to conclude that the blast cells may derive from the same clone as the proliferating lymphocytes of the chronic phase.

This work was supported in part by grants from the Institut National de la Santé et de la Recherche Médicale (I.N.S.E.R.M.) and from the Délégation Générale à la Recherche Scientifique et Technique (D.G.R.S.T.).

We thank Mrs. Sylvaine Labaume for skilled technical help.

\section{References}

Andersen, E., and Videbaek, A. (1970). Scandinavian fournal of Haematology, 7, 201

Boggs, D. R., Wintrobe, M. M., and Cartwright, G. E. (1962). Medicine, 41, 163.

Catovsky, D., and Galton, D. A. G. (1971). Lancet, 1, 478.

Diamond, H. D., Craver, L. F., Woodard, H. Q., and Parks, G. H. (1950).

Lancet, 3, 778.
Kyle, R. A., Pierce, R. V., and Bayrd, E. D. (1970). New England Fournal of Medicine, 283, 1121 .

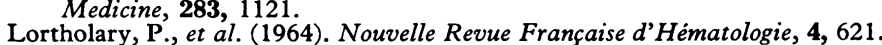

Lortholary, P., et al. (1964). Nouvelle Revue Française d'Hématologie, 4, 621.

Lortholary, P., et al. (1966). Nouvelle Revue Française d'

Osgood, E. E. (1964). Fournal of Laboratory and Clinical Medicine, 64, 560.

Osgood, E. E. (1964). Fournal of Laboratory and Clinical Medicine, 64, 560.
Pequignot, H., Levy, J. P., Girerd, R., Cocheton, J. J., and Ruet, J. C. (1970). Semaine des Hôpitaux, 46, 2678.
Pequignot, H., Levy, J. Pirerd, R., Coch

Preud'Homme, J. L., Klein, M., Verroust, P., and Seligmann, M. (1971). Revue Européenne d'Etudes Cliniques et Biologiques, 16, 1025.

Preud'Homme, J. L., and Seligmann, M. (1972 a). Blood, 40, 777.

Preud'Homme, J. L., and Seligmann, M. (1972 b). fournal of Clinical Investigation, 51, 701 .

Preud'Homme, J. L., and Seligmann, M. (1972 c). Proceedings of the National Academy of Sciences of the United States of America, 69, 2132. 